\title{
Isolation and characterization of a marine bacterium Vibrio diabolicus strain L2-2 capable of biotransforming sulfonamides
}

\author{
Qiaoning Wang, ${ }^{\mathrm{a}, \mathrm{b}, \mathrm{e}}$, Yaru Jiang ${ }^{\mathrm{a}}$, Hongdan Wang ${ }^{\mathrm{a}, \mathrm{b}}$, Xianbo Chang ${ }^{\mathrm{d}}$, Min $\mathrm{Lv}^{\mathrm{a}, \mathrm{b}, * *}$, \\ Lingxin Chen ${ }^{\mathrm{a}, \mathrm{b}, \mathrm{c}, *}$ \\ ${ }^{\text {a }}$ CAS Key Laboratory of Coastal Environmental Processes and Ecological Remediation, Research Centre for Coastal Environmental Engineering and Technology, Yantai \\ Institute of Coastal Zone Research, Chinese Academy of Sciences, Yantai, 264003, China \\ ${ }^{\mathrm{b}}$ Shandong Key Laboratory of Coastal Environmental Processes, Yantai Institute of Coastal Zone Research, Chinese Academy of Sciences, Yantai, 264003, China \\ ${ }^{\mathrm{c}}$ Center for Ocean Mega-Science, Chinese Academy of Sciences, Qingdao, 266071, China \\ d College of Environmental and Material Engineering, Yantai University, Yantai, 264005, China \\ e University of Chinese Academy of Sciences, Beijing, 100049, China
}

\section{A R T I C L E I N F O}

\section{Keywords:}

Sulfonamides

Vibrio diabolicus strain L2-2

Acetylation

Biotransformation

Arylamine $N$-Acetyltransferase

\begin{abstract}
A B S T R A C T
Sulfonamides (SAs) have attracted much attention because of their high detection rates in natural water. In this study, a marine bacterium Vibrio diabolicus strain L2-2 was isolated which could metabolize 9 SAs to a different extent. Compared with SAs and their analogs, SAs with $\mathrm{N}$-oxides of heterocyclic structure were easier to be transformed to their $N^{4}$-acetylated metabolites or their isoxazole ring rearrangement isomers by strain L2-2. And, gene $v$ dnatA and $v$ dnat $G$ were likely to be the key genes in SAs acetylation process, which might code Arylamine $N$-acetyltransferase. The biotransformation rates of sulfathiazole(STZ), sulfamonomethoxine(SMT), sulfadiazine (SDZ), sulfamethoxazole(SMX) and sulfisoxazole(SIX) could reach $29.39 \pm 5.63,24.97 \pm 4.45$, $79.41 \pm 4.05,64.64 \pm 1.71,32.82 \pm 4.46 \%$ in 6 days, respectively. Besides, the overall optimal conditions for SAs biotransformation were less than $100 \mathrm{mg} / \mathrm{L}$ for total SAs in neutral or weakly alkaline medium with the salinity of $10-20 \%$ and additional nutrients like glucose, sucrose or glycerine. Furthermore, toxicity was demonstrated to be significantly reduced after biotransformation. Together, this study introduced a strategy to use $V$. diabolicus strain L2-2 to realize simultaneous removal and detoxification of multiple SAs in freshwater and seawater, and revealed SAs removal pathways and relevant molecular mechanism.
\end{abstract}

\section{Introduction}

With the improvement of analytical techniques and molecular biology, antibiotics have received increasing attention because of their widespread presence and danger to human beings. Antibiotics in the environment will continuously inhibit microorganisms even lead to the spread of resistant genes and the increase of bacteria antimicrobial resistance (AMR), which has been considered as a significant threat to agriculture, and even to human health (Cabello et al., 2013; Xiong et al., 2015).

Sulfonamides (SAs) are a class of synthetic antibiotics which include $p$-aminobenzenesulfonamide ( $p$-ABS) and its derivatives. The main antimicrobial mechanism of SAs is to suppress dihydrofolic acid synthesis by competing with p-aminobenzoic for dihydrofolic acid synthetase to inhibit the growth of the bacteria rather than kill them (Ingerslev and Halling-Sørensen, 2000). SAs have been widely used in animal husbandry, aquaculture and healthcare (García-Galán et al., 2008; Gothwal and Shashidhar, 2015; Segura et al., 2009) and accounted for over onefifth of the total consumption of veterinary antibiotics in many countries (Sarmah et al., 2006). Their production has also increased from 5000 tons in the 1980 s to 20000 tons in 2003 in China (Mo et al., 2017). Extensive research confirmed that the absorption rates of SAs ingested by human and animals are very low, up to $80 \%$ of consumed antibiotics could be excreted through urine and feces, and up to $75 \%$ of antibiotics used in aquaculture could enter into the surrounding environment (Gaze et al., 2017). Because of their polarity and low adsorption (Müller et al., 2013), most SAs are easier to enter aqueous environments, and therefore SAs have been frequently detected in

\footnotetext{
${ }^{*}$ Corresponding author. CAS Key Laboratory of Coastal Environmental Processes and Ecological Remediation, Research Centre for Coastal Environmental Engineering and Technology, Yantai Institute of Coastal Zone Research, Chinese Academy of Sciences, Yantai, 264003, China.

${ }^{* *}$ Corresponding author. CAS Key Laboratory of Coastal Environmental Processes and Ecological Remediation, Research Centre for Coastal Environmental Engineering and Technology, Yantai Institute of Coastal Zone Research, Chinese Academy of Sciences, Yantai, 264003, China.

E-mail addresses: mlv@yic.ac.cn (M. Lv), lxchen@yic.ac.cn (L. Chen).
} 
estuary water, sediment (Zheng et al., 2011; Shi et al., 2014; Zhang et al., 2015), and even in drinking water (Ye et al., 2007; Batt et al., 2006). The widespread presence of SAs could lead to the contamination of antibiotic resistance genes (ARGs) and changes in bacterial community structure. Typical sulfonamide ARG sul has been reported to be dominant among tetracycline, sulfonamide and quinolone ARGs (Yan et al., 2018). The contamination of SAs has also been demonstrated to affect bacterial community structure by increasing the abundance of Epsilonproteobacteria, while decreasing the abundance of Beta and Gamma proteobacteria and Firmicutes (Novo et al., 2013). Therefore, it is very important to develop strategies to remove SAs from the environment.

To date, treatment technologies to SAs included ozonation, anaerobic process, electrochemical oxidation, Fenton oxidation, PhotoFenton, chlorination, photolysis, photocatalysis, adsorption, and biodegradation (Homem and Santos, 2011). Although some SAs have been suggested to be resistant to biodegradation and hydrolysis (Sukul and Spiteller, 2006), microbial degradation and biotransformation were still considered to be the main mechanism of removing SAs in the natural environment as well as in wastewater treatments (Yang et al., 2016; Boreen et al., 2004). Their metabolic products and toxic mechanism under the action of biological metabolism were research priorities, and the microbial degradation pathway of SAs had been analyzed in detail (Wang and Wang, 2018a), but most studies focused on activated sludge (Müller et al., 2013; Yang et al., 2012; Men et al., 2017). Few studies have been done on isolated SAs bio-removal strains, and most of which were isolated from activated sludge (Wang and Wang, 2018b) and freshwater (Reis et al., 2018a).

In this study, the main objective was to isolate, identify and characterize the SAs-removal bacterial strains from estuary water. Besides, we explore the removal mechanisms by analyzing the metabolic products of SAs, key genes of isolated bacterial strains, and also assess the toxicity of SAs and their metabolic products. What's more, the factors influencing SAs removal efficiency will also be investigated in this study. To the best of our knowledge, this will be the first report on isolates involved in the removal of sulfisoxazole (SIX) and sulfamonomethoxine (SMT) in seawater, and this also will be the first report on marine bacterium Vibrio diabolicus about its sulfonamides removal capacity.

\section{Materials and methods}

\subsection{Chemicals and media}

16 SAs and analogs of them including aniline (AN), sulfanilamide (SA), $p$-aminobenzene sulfonic acid (pASC), 4-methylsulfonylaniline (MSA), sulfaguanidine (SGD), sulfamethoxazole (SMX), SIX, sulfacetamide (SCM), sulfathiazole (STZ), sulfadiazine (SDZ), sulfapyridine (SPD), sulfamerazine (SMZ), sulfamethazine (SMZ-2), sulfadimethoxine (SDM), SMT, sulfadoxine (SDX), $N^{4}$-acetylsulfamethoxazole $\left(N^{4}\right.$ AcSMX) were purchased from J\&K Chemical Inc. (Beijing, China). $N^{1}$ acetylsulfamethoxazole ( $N^{1}$-AcSMX) was purchased from Merck \& Co.,
Inc. (Darmstadt, Germany). Acetonitrile (HPLC-grade) was purchased from CNW Technologies (Duesseldorf, Germany). All other chemicals used were at the highest purity available commercially.

The growth medium (2216E seawater medium) consisted of (per liter of filtered seawater, $\mathrm{pH} 7.2$ ) tryptone $5 \mathrm{~g}$, yeast extract $1 \mathrm{~g}$ and $\mathrm{FePO}_{4} 0.01 \mathrm{~g}$. The minimal medium (liquid) consisted of (per liter of filtered seawater, $\mathrm{pH}$ 7.2) $\mathrm{KH}_{2} \mathrm{PO}_{4} 3 \mathrm{~g}, \mathrm{Na}_{2} \mathrm{HPO}_{4} \cdot 7 \mathrm{H}_{2} \mathrm{O} 12.8 \mathrm{~g}, \mathrm{NaCl}$ $0.5 \mathrm{~g}, \mathrm{NH}_{4} \mathrm{Cl} 1.5 \mathrm{~g}, \mathrm{MgSO}_{4} 0.3 \mathrm{~g}, \mathrm{CaCl}_{2} 0.0112 \mathrm{~g}$, EDTA-Fe $1 \mathrm{~mL}$ (per liter of distilled water, consisting of $\mathrm{FeSO}_{4} \cdot 7 \mathrm{H}_{2} \mathrm{O} 0.0246$ g, EDTA $0.0331 \mathrm{~g}$ ) and trace elements $1 \mathrm{~mL}$ (per liter of distilled water, containing $\mathrm{H}_{3} \mathrm{BO}_{3} 0.05 \mathrm{~g}, \mathrm{Na}_{2} \mathrm{MoO}_{4} \cdot 2 \mathrm{H}_{2} \mathrm{O} 0.002 \mathrm{~g}, \mathrm{MnCl}_{2} 0.002 \mathrm{~g}$, $\mathrm{CoCl}_{2} \cdot 6 \mathrm{H}_{2} \mathrm{O} 0.00002 \mathrm{~g}, \mathrm{ZnSO}_{4} \cdot 7 \mathrm{H}_{2} \mathrm{O} 0.004 \mathrm{~g}, \mathrm{CuSO}_{4} \cdot 5 \mathrm{H}_{2} \mathrm{O} 0.001 \mathrm{~g}$ and $\mathrm{KI} 0.001 \mathrm{~g}$ ). LB medium consisted of (per liter of distilled water, $\mathrm{pH} 7.2$ ) peptone $10 \mathrm{~g}$, yeast extract powder $5 \mathrm{~g}$ and $\mathrm{NaCl} 10 \mathrm{~g}$. All solid growth medium contained the same ingredients as the liquid medium amended with agar powder $(1.5 \% \mathrm{wt} / \mathrm{vol})$. Phosphate buffer solution (PBS) consisted of (per liter of distilled water, $\mathrm{pH}$ 7.2) $\mathrm{NaCl} 8 \mathrm{~g}$, $\mathrm{Na}_{2} \mathrm{HPO}_{4} \cdot 12 \mathrm{H}_{2} \mathrm{O} 3.63 \mathrm{~g}$ and $\mathrm{KH}_{2} \mathrm{PO}_{4} 0.24 \mathrm{~g}$. All of the above mediums and buffer solutions were autoclave sterilized.

\subsection{Isolation and identification of bacterial strains}

Because SMX was frequently detected in the environment, the report by the U.S. Geological Survey showed that SMX was the most common SAs in wastewater (Kolpin et al., 2002), so SMX was chose as the representative of SAs to isolate SAs removal bacteria and explore the removal mechanism. The bacteria were isolated from the estuary water of Guangdang River in Yantai of China. $10 \mathrm{~L}$ estuary water was filtered with $0.45 \mu \mathrm{m}$ membrane and the collected marine bacteria on the membrane were incubated in the minimal medium supplemented with $20 \mathrm{mg} / \mathrm{L}$ SMX at $30{ }^{\circ} \mathrm{C}, 160 \mathrm{rpm}$. After acclimation by repeating the procedure 5 times, the strains were isolated by plating the acclimated bacteria onto the solid growth medium supplemented with $20 \mathrm{mg} / \mathrm{L}$ SMX. Through repeatedly screening, the strain with the highest SMX removal efficiency was selected and numbered as L2-2. The morphology of strain L2-2 was observed by scanning electron microscopy (Hitachi S-4800, Japan Tokyo). The 16S rRNA gene sequence of strain L2-2 was aligned with the related sequences from GenBank and EzBioCloud databases and the phylogenetic tree was constructed using MEGA5.0 software. All primer sequences used in this study were shown in Table 1.

\subsection{Bio-removal experiments}

Strain L2-2 cells were cultured for $12 \mathrm{~h}$ in the growth medium, collected by centrifugation at $8000 \mathrm{rpm}$ for $3 \mathrm{~min}$, and washed with sterile PBS for 3 times. Then the cells were incubated in the minimal medium containing $10 \mathrm{mg} / \mathrm{L}$ SMX with an initial cell concentration of $10^{8} \mathrm{CFU} / \mathrm{mL}$. All cultures were incubated in the incubator shaker at $160 \mathrm{rpm}$ and $30{ }^{\circ} \mathrm{C}$. Samples were collected after a day, analyzed for SMX concentration by HPLC after filtration, and the ones which could be metabolized by strain L2-2 were further analyzed for their

Table 1

Primers used in this study.

\begin{tabular}{lll}
\hline Gene name & Forward primer & Reverse primer \\
\hline 16 S rRNA & AGAGTTTGATCCTGGCTCAG & GGTTACCTTGTTACGACTT \\
16 S rRNA-RT & GCACAAGCGGTGGAGCATGTGG & CGTGTGTAGCCCTGGTCGTA \\
$v$ dnatA & GCGTGTTTTAGCGACCTTGA & CCCATCATAACCGGCTGACT \\
$v$ dnat $B$ & TTGCTGACGACAAGCACAAA & GCCAAGGGACAGGTACAAAGA \\
$v$ dnatC & AGGCGAGTTTCAACGACGATA & TCGCTTGATTTCCAATCCCT \\
$v$ dnatD $D$ & GCCATTACCCTGCGTCAAGA & CGACCAAGTGCATCGCTTTT \\
$v$ dnatE & CGCACTATGAAGCTGAACCG & GACGACCTTCTTTGCGAGC \\
$v$ dnatF & GGTAGTCGGCTTTTTAACCGC & GCTCACAAGCCTCAAGCAGT \\
$v$ nat $G$ & TGACGCTGGATGAACAAGCA & GTCCGTTCCATCCGTTGACA \\
\hline
\end{tabular}


metabolites by HPLC-ESI-MS/MS. The ability of strain L2-2 removal AN, SA, pASC, MSA, SGD, SIX, SCM, STZ, SDZ, SPD, SMZ, SMZ-2, SDM, SMT and SDX were tested with the same methods of SMX. The bioremoval rate (biotransformation rate) was calculated as the following equation:

$R=\frac{C_{0}-C_{\mathrm{t}}}{C_{0}} \times 100$

where $R$ is the bio-removal rate (biotransformation rate) of SAs and its analogs (\%); $C_{0}$ is the initial concentration of SAs $(\mathrm{mg} / \mathrm{L})$; and $C_{t}$ is the remaining concentration of SAs at time $t(\mathrm{mg} / \mathrm{L})$.

SAs with high bio-removal rates including STZ, SMT, SDX, SMX and SIX were further selected to investigate their bio-removal process in coexistence status. The experiment was conducted in the same conditions as discussed above except that the minimal medium was added with the 5 SAs all in $4 \mathrm{mg} / \mathrm{L} 1 \mathrm{~mL}$ of sample was collected per day for 6 days and analyzed by HPLC. The same medium containing SAs with autoclaved bacterial cells was used as control.

\subsection{Effects of influential factors on SAs bio-removal}

Potential influential factors including SAs initial concentration, $\mathrm{pH}$, salinity, additional carbon resources, and nitrogen sources were selected to investigate their effects on SAs bio-removal. To determine the effect of SAs initial concentration, strain L2-2 was inoculated into minimal medium solution with different initial concentrations of SAs ranging from 0.5 to $50 \mathrm{mg} / \mathrm{L}$. To determine the effect of $\mathrm{pH}$, strain L2-2 was inoculated into PBS with $\mathrm{pH}$ ranging from 5.0 to 9.0 containing $4 \mathrm{mg} / \mathrm{L}$ SAs. To determine the effect of salinity, strain L2-2 was inoculated into PBS adding with seawater ranging from $0 \%$ to $100 \%$ containing $4 \mathrm{mg} / \mathrm{L}$ SAs. To determine the effect of additional carbon and nitrogen sources, strain L2-2 was inoculated into minimal medium containing $4 \mathrm{mg} / \mathrm{L} \mathrm{SAs}$ and $1 \mathrm{~g} / \mathrm{L}$ sterile nutriment which respectively was glucose, sucrose, starch, palmitic acid, linoleic acid, formic acid, methyl alcohol and yeast extract powder, peptone, casein, acid hydrolyzed casein, glycine, and $\mathrm{NH}_{4} \mathrm{Cl}$. All experiments were conducted in triplicate with initial cell concentrations of $10^{8} \mathrm{CFU} / \mathrm{mL}$ and autoclaved strain L2-2 cells as control. Samples were collected at 0 and 4 days for SAs analysis. It should also be pointed out that SAs included STZ, SMT, SDX, SMX and SIX.

\subsection{Toxicity analysis}

To investigate the changes in toxicity to strain Escherichia coli (standard strain purchased from BeNa Culture Collection (Beijing, China), which was the subculture strain of E. coli CMCC44103) after strain L2-2 metabolism, the supernatant with $20 \mathrm{mg} / \mathrm{L}$ single and mixed STZ, SMT, SDX, SMX, SIX was collected before and after metabolism for 10 days by strain L2-2. The collected supernatant, mixed with an equal volume of $\mathrm{LB}$ medium was inoculated with $0.02 \mathrm{OD}_{600} E$. coli and cultivated at $28{ }^{\circ} \mathrm{C}, 160 \mathrm{rpm}$ for $10 \mathrm{~h} . N^{4}$-AcSMX was also tested using the above method. The supernatant of strain L2-2 without SAs was used as the control. Toxicities were expressed by $E$. coli growth inhibitory rate, which was calculated by the following equation:

$I=\frac{N_{\mathrm{C}}-N_{\mathrm{D}}}{N_{\mathrm{C}}} \times 100$

where $I$ is $E$. coli growth inhibitory rate (\%); $N_{\mathrm{C}}$ is $E$. coli cell concentration of the control group; $N_{D}$ is $E$. coli cell concentration of the experimental group with SAs.

\subsection{Genome sequencing and genes related to sulfonamide biotransformation}

The genome of $V$. diabolicus strain L2-2 was purified using a Bacterial Genomic DNA Extraction Kit (Solarbio) and quantified with
Quant-iT PicoGreen dsDNA Assay Kit (ThermoFisher). Multiplexed DNA libraries were constructed with TruSeq DNA Sample Prep Kit (Illumina), and sequenced using Illumina Hiseq with paired-end, $2 \times 150$ bp sequencing mode. De novo assembly was performed using A5-MiSeq (Coil et al., 2015) and SPAdes (Bankevich et al., 2012) and corrected with Pilon software (Walker et al., 2014). Gene prediction was conducted using GeneMarkS (Besemer et al., 2001), functional annotation was performed by sequence alignment comparing with NCBI NR databases (Buchfink et al., 2015).

According to genome gene prediction and functional annotation, genes that might be related to SMX biotransformation were preliminaryly screened with $N$ - acetyltransferase. Multiple genes performed protein sequence alignment with the Resistance Gene Identifier (RGI) in the Comprehensive Antibiotic Resistance Database (CARD) for further screening. Finally, 7 genes were selected and their expressions in sulfonamide stress were researched. For gene expression studies, cells of strain L2-2 with and without $10 \mathrm{mg} / \mathrm{L}$ SMX treatment were collected at $0 \mathrm{~h}, 24 \mathrm{~h}$ and $48 \mathrm{~h}$. The total RNA was extracted using RNA prep Pure Cell/Bacteria Kit (Tiangen, China) and reversed transcription was performed using PrimeScript RT Reagent Kit (Takara, Japan). Expression of hypothetical SMX biotransformation genes was semi-quantified using TB Green Premix Ex Taq (Takara, Japan), the $2^{-\Delta \Delta \mathrm{Ct}}$ method (Schmittgen and Livak, 2008), by RT-PCR (QuantStudio 5, ThermoFisher, America). Meanwhile, a fragment of the 16S rRNA was used to normalize the mRNA level of each gene (16S rRNA-RT) (Zhang et al., 2013). For RT-PCR analysis, one-way ANOVA tests were used by SPSS. Statistically significant difference was tested at $\mathrm{P}$ values $<0.05$.

\subsection{Analytical methods}

SAs concentrations were analyzed by Agilent 1260 Infinity II HPLC (Agilent, America) equipped with an Agilent reversed-phase column SBC18(4.6 $\times 150 \mathrm{~mm}, 5 \mu \mathrm{m})$ and a diode-array detector operating at a wavelength of $270 \mathrm{~nm}$. The flow rate was $0.9 \mathrm{~mL} / \mathrm{min}$ with a gradient mode of $\mathrm{t}=0 \mathrm{~min}(20: 80), \mathrm{t}=7 \mathrm{~min}(20: 80), \mathrm{t}=8 \mathrm{~min}$ (43:57) and $\mathrm{t}=11 \mathrm{~min}(20: 80)$ for acetonitrile and $0.4 \%$ ethanoic acid, respectively. The injection volume was $10 \mu \mathrm{L}$ and the column temperature was set as $35{ }^{\circ} \mathrm{C}$.

The metabolic products were identified using LCQ Fleet HPLC-ESIMS/MS (Thermo Fisher Scientific, America). The LC conditions were similar with the method as described above, except that the flow rate was $0.6 \mathrm{~mL} / \mathrm{min}$ and gradient mode was adjusted to $\mathrm{t}=0 \mathrm{~min}(20: 80)$, $\mathrm{t}=4 \min (20: 80), \mathrm{t}=8 \min (43: 57), \mathrm{t}=12 \min (43: 57)$ and $\mathrm{t}=15 \mathrm{~min}$ (20:80) for acetonitrile and $0.4 \%$ ethanoic acid. The mass spectrometer was operated in positive ion mode at full scan $\mathrm{m} / \mathrm{z}$ range of $100-1000$, ion spray voltage $3 \mathrm{kV}$, spray voltage $5 \mathrm{kV}$ and capillary temperature $270{ }^{\circ} \mathrm{C}$.

\section{Results and discussion}

\subsection{Isolation and identification of the SMX bio-removal marine bacteria}

After the duplicate screening, a marine bacterial strain L2-2 showing maximum efficiency of SMX removal was isolated. The strain L2-2 was a gram-negative bacterium, atrichosis and shot rod (Fig. 1a). The filtered high-quality data sequenced using Illumina Hiseq were de novo assembled with $237 \times$ depth of coverage. The genome of strain L2-2 was composed of 77 contigs with total sequence length of $5.28 \mathrm{Mbp}$ and the GC content of $44.72 \%$. The genome sequence and other information of strain L2-2 have been submitted to NCBI with accession number JAANXJ000000000. By comparison with sequences in the GenBank database and type strain sequences in the EZBioCloud database, the 16S rRNA genes of strain L2-2 showed a $99.80 \%$ similarity to those of $V$. alginolyticus, whose accession number was CP014053.1. The Neighbour-joining tree based on 16S rRNA gene sequences showed a closer relationship with $V$. alginolyticus (ATCC1749 ${ }^{\mathrm{T}}$ ), 

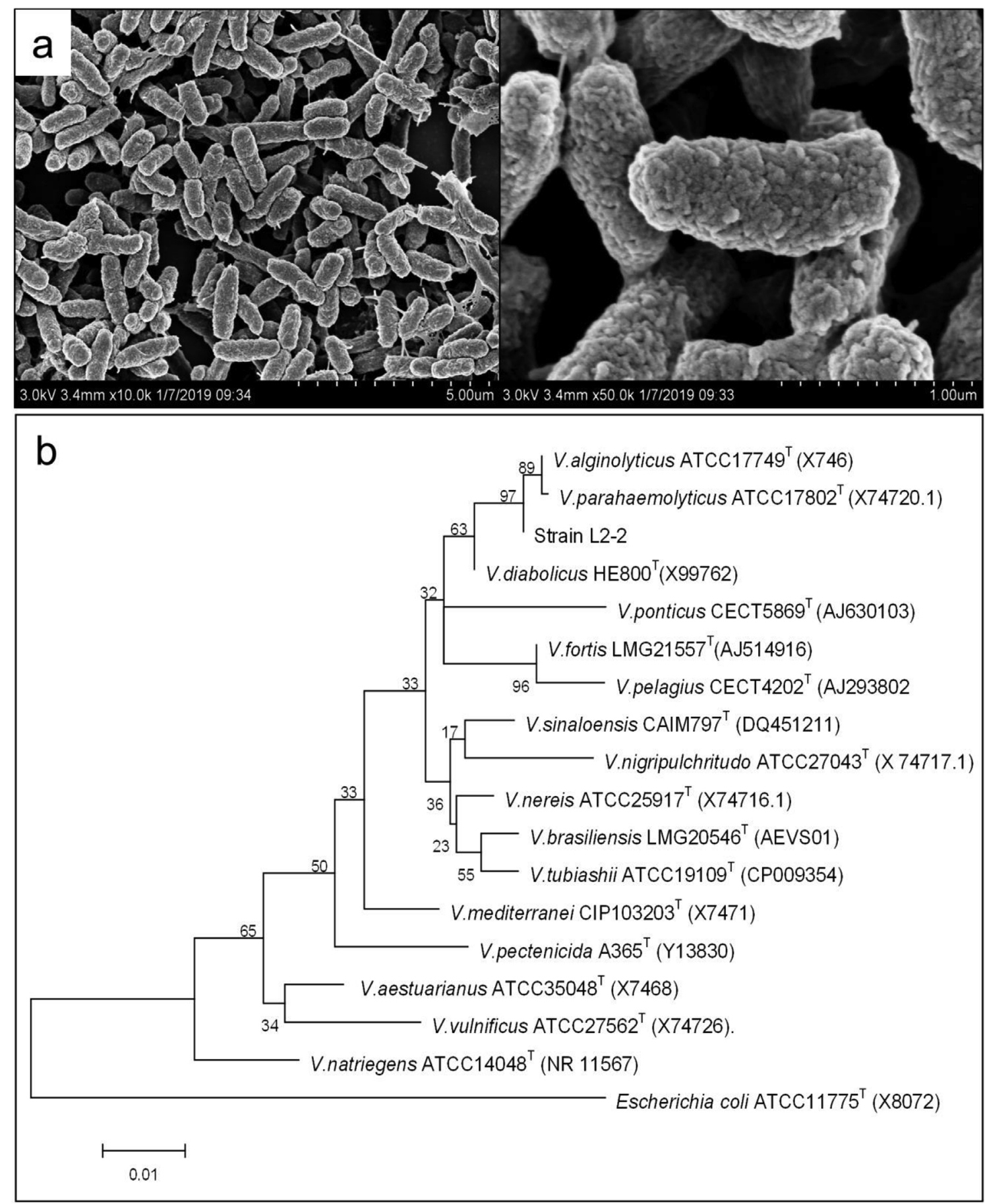

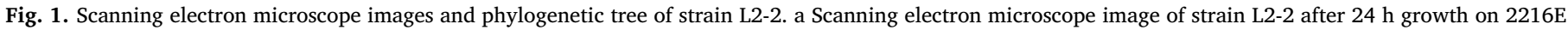

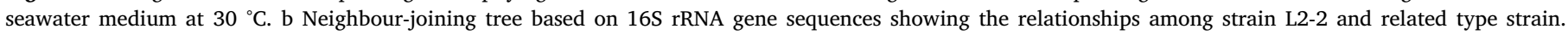

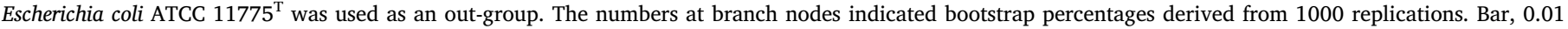
accumulated changes per nucleotide position.

V. parahaemolyticus (ATCC17802 $\left.2^{\mathrm{T}}\right)$, and $V$. diabolicus $\left(\mathrm{HE} 800^{\mathrm{T}}\right)$ (Fig. 1b). But, by using average nucleotide identity (ANI), the genome of strain L2-2 was $97.961 \%$ identical to the type genome of $V$. diabolicus (PRJNA224116), with 86.4\% coverage of the genome (Federhen et al., 2016; Ciufo et al., 2018). In order to sufficiently identify strain L2-2, its genome was compared with other genomes using the Pathosystems Resource Integration Center (PATRIC) web-based service, and the result showed that strain L2-2 was most similar to V. diabolicus strain FDAARGOS_96 (PATRIC Genome ID: 50719.19). The genome-scale phylogenetic tree also built using PATRIC, and the tree showed that strain L2-
2 had a closer relationship with $V$. diabolicus strain JBS-8-11-1 (PATRIC Genome ID: 50719.45) (Fig. S1). So strain L2-2 was identified as $V$. diabolicus, preserved in China General Microbiological Culture Collection Center with preservation number CGMCC No.18031. Its 16S rRNA partial sequence was submitted to GenBank with accession number MN180830.

The SAs bio-removal strains reported previously included Escherichia sp., Acinetobacter sp. (Zhang et al., 2012a), Achromobacter sp. [38 (Wang and Wang, 2018b), Shewanella oneidensis (Mao et al., 2018), Microbacterium sp. (Ricken et al., 2015), Proteobacteria sp. (Reis 
Table 2

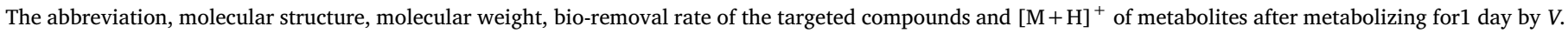
diabolicus strain L2-2.

\begin{tabular}{|c|c|c|c|c|c|}
\hline Compound (Abbreviation) & Molecular structure & Molecular weight & {$[\mathrm{M}+\mathrm{H}]^{+}$} & {$[\mathrm{M}+\mathrm{H}]^{+}$of metabolites } & Biotransfor-mation rate \\
\hline Aniline (AN) & & 93.14 & / & / & 0 \\
\hline Sulfanilamide (SA) & & 172.20 & / & / & 0 \\
\hline$p$-aminobenzene sulfonic acid ( $p$ ASC) & & 173.20 & / & / & 0 \\
\hline 4-Methylsulfonylaniline (MSA) & & 171.22 & / & / & 0 \\
\hline Sulfaguanidine(SGD) & & 214.24 & / & / & 0 \\
\hline Sulfamethoxazole (SMX) & & 253.27 & 254.15 & 296.17 & $22.42 \%$ \\
\hline Sulfisoxazole (SIX) & & 267.30 & 268.10 & 310.16 & $20.32 \%$ \\
\hline Sulfacetamide (SCM) & & 214.24 & 215.05 & 257.09 & $8.95 \%$ \\
\hline Sulfathiazole (STZ) & $\mathrm{H}_{2}$ & 255.31 & 256.15 & 298.15 & $9.96 \%$ \\
\hline Sulfadiazine (SDZ) & & 250.27 & / & / & 0 \\
\hline Sulfapyridine (SPD) & & 249.28 & 250.11 & 292.10 & $5.43 \%$ \\
\hline Sulfamerazine (SMZ) & & 264.30 & 265.15 & 307.16 & $8.79 \%$ \\
\hline Sulfamethazine (SMZ-2) & & 278.33 & / & / & 0 \\
\hline
\end{tabular}


Table 2 (continued)

\begin{tabular}{|c|c|c|c|c|c|}
\hline Compound (Abbreviation) & Molecular structure & Molecular weight & {$[\mathrm{M}+\mathrm{H}]^{+}$} & {$[\mathrm{M}+\mathrm{H}]^{+}$of metabolites } & Biotransfor-mation rate \\
\hline Sulfadimethoxine (SDM) & & 310.32 & 311.17 & 353.16 & $38.77 \%$ \\
\hline Sulfamonomethoxine (SMT) & & 280.30 & 281.19 & 323.21 & $13.71 \%$ \\
\hline Sulfadoxine (SDX) & & 310.32 & 311.16 & 353.19 & $38.96 \%$ \\
\hline
\end{tabular}

et al., 2018a), Phanerochaete chrysosporium (Guo et al., 2014), Pseudomonas psychrophila (Jiang et al., 2014), Pseudomonas sp. (Zhang et al., 2012b), Alcaligenes faecalis (Zhang et al., 2016), fungus Trametes versicolor (Rodríguez-Rodríguez et al., 2012) and some others (Wang and Wang, 2018a; Chen and Xie, 2018), and some reported bacterial strain with 16S rRNA sequence were listed and compared to strain L2-2 (Fig. S2). According to the phylogenetic tree of strain L2-2 and other strains that had SAs bio-removal capacity confirmed by previous reports, strain L2-2 had a high homology just with Enterobacter sp. strain HS21 (Zhang et al., 2012a), but there were no reported degradation pathway or the key genes involved in SAs biodegradation about strain HS21. It should be pointed out that, these bacteria were mostly isolated from the freshwater environment, but strain L2-2, isolated in estuary water in this study, belonged to $V$. diabolicus, whose bio-removal ability towards SAs have not been reported.

\subsection{Bio-removal of SAs by strain L2-2 and their metabolites}

As shown in Table 2, pABS with nitrogen heterocyclic structure or amide structure could be metabolized by strain L2-2, while $p$ ABS (SA) and aniline (AN) could not be metabolized. Among the 16 SAs, 9 SAs could be bio-removed to different extents by strain L2-2 in 1 day, and the order of bio-removal efficiencies was SDX $>$ SDM $>$ SMX $>$ SIX $>$ SMT $>$ STZ $>$ SCM $>$ SMZ $>$ SPD. Although previous research showed that SAs with a penta-heterocycle exhibited a higher photodegradation rate than those with a hexa-heterocycle because of their higher electron densities (Lian et al., 2015), our study showed that SDX and SDM with hexa-heterocycle structure had the highest biodegradation efficiency, suggesting that the mechanisms might be different between bio-removal and photodegradation.

Compared with the corresponding SAs, the $[\mathrm{M}+\mathrm{H}]^{+}$values of all the detected metabolites increased by 42.0 (Table 2, Fig. S3), preliminarily indicating the occurrence of acetylation because the increased molecular weight matched with the acetyl group and acetylsulfonamide were the common metabolite of sulfonamide in animal, human and also in the environment (Harnisch et al., 2013; Radke et al., 2009) $N^{4}$-AcSMX and $N^{1}$-AcSMX were the mostly reported acetylated metabolites of SMX (Geng et al., 2018), but they were not detected in this study. Interestingly, the SMX metabolite was identical to the product of $N^{4}$-AcSMX after strain L2-2 metabolizing (Fig. S4). According to previous research, isoxazole ring rearrangement could construct an SMX isomer in the water/sediment system and ozone treatment (Su et al., 2016; Gómez-Ramos et al., 2011). As there was no other chromatographic peak with the same molecular weight as SMX, SMX was more likely to be transformed to $N^{4}$-AcSMX first and then quickly transformed to its isomer with isoxazole ring rearrangement by strain L2-2 (Fig. S5). According to the characteristics of chromatogram and mass spectrogram, the products of other SAs could be speculated to their $N^{4}$-acetylation products or $N^{4}$-acetylation isomer metabolized by strain L2-2 as well (Fig. 2). There were substantial differences in SMX metabolic pathways by different bacterial species, and the main pathways could be summed up as ammonia oxidation, ammonia hydroxylation, sulfate reduction, and mineralization decomposition (Wang and Wang, 2018a). $N^{4}$-acetylation of SAs was one of the ammonia oxidation, and had also been widely reported in microorganisms (Zhang et al., 2016; Kassotaki et al., 2016; Gauthier et al., 2010). Some bacterium strains could only transform SMX to $N^{4}$-acetyl-SMX without other products just like strain L2-2. Reis et al. found that some Aeromonas sp., Kluyvera sp., and Raoultella sp. from mineral drinking water could transform SMX into the lesser toxic derivative $N^{4}$-acetyl-SMX and no further degradation products were found just like strain L2-2 (Reis et al., 2018a). Zhang et al. found that $N^{4}$-acetylation was one of the SMX removal mechanisms by Alcaligenes faecalis, the other products were N-hydroxy SMX, and there were no other further degradation products (Zhang et al., 2016). But some bacterium strains could transform SMX not only to their acetylation products but also other products. Gauthier et al. found that Rhodococcus rhodochrous and Aspergillus niger could co-metabolized SMX to $N^{4}$-acetyl-SMX and further to $N^{4}$-hydroxy-acetyl-SMX (Gauthier et al., 2010). Kassotaki et al. found SMX could be transformed to 4-Nitro SMX, Desamino-SMX, $N^{4}$-AcetylSMX and finally most SMX was removed by co-metabolism of ammoniaoxidizing bacteria (Kassotaki et al., 2016). Besides what's mentioned above, SMX could also be metabolized by other pathways. For example, Achromobacter denitrificans PR1 and Leucobacter sp. GP could degrade SMX to 4-aminophenol (Reis et al., 2018b), while Pseudomonas psychrophila HA-4 could degrade SMX to aniline, 4-aminothiophenol, sulfanilamide, and 3-amino-3-methylsisoxazole (Jiang et al., 2014). Researches showed that some bacterial species could perform multiple metabolic pathways towards SMX while some could only perform one. But for most bacterial species, one metabolic pathway was relatively common, and multiple pathways were common in mixed bacterial species.

Considering that SAs coexisted in natural environments, it is necessary to investigate their bio-removal efficiency in co-existence status. Since SAs including STZ, SMT, SDX, SDM, SMX and SIX showed higher bio-removal efficiency, and SDM is an isomer of SDX with similar properties, 5 SAs including STZ, SMT, SDX, SMX and SIX were selected. 5 SAs with autoclaved bacterial cells showed no obvious 


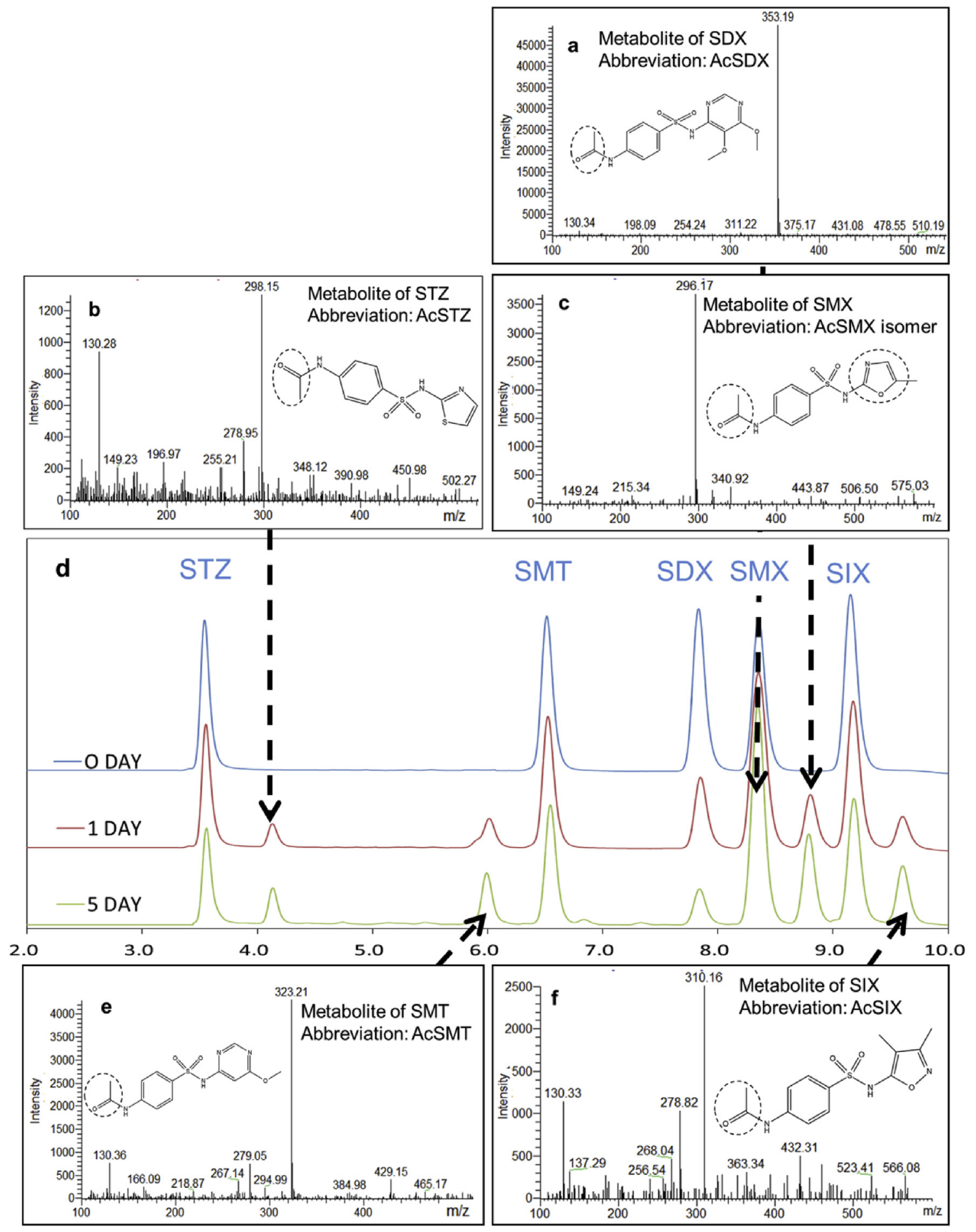

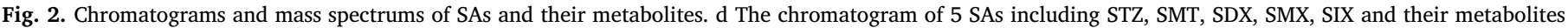

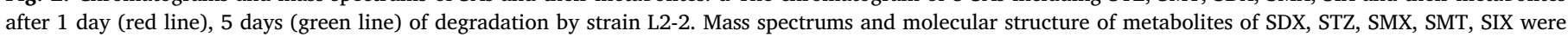
shown in a, b, c, e, f respectively. (For interpretation of the references to color in this figure legend, the reader is referred to the Web version of this article.)

natural degradation in 6 days (Fig. S6). The chromatogram and mass spectrogram of 5 SAs were shown in Fig. 2 during the metabolic process by stain L2-2. As shown in Fig. 3, all the 5 SAs could be transformed quickly on the first day, and then the biotransformation efficiency decreased gradually day by day. The biotransformation rates of SDX and SMX were apparently higher than STZ, SIX and SMT, which were generally consistent with the results when conducted separately (Table 2). The biotransformation rates could reach to $79.41 \%, 64.64 \%$, $29.39 \%, 32.82 \%$ and $24.97 \%$ for SDX, SMX, STZ, SIX, SMT, respectively, in 6 days. There were significant differences in the SAs bio-removal efficiencies by different bacterial strains. For example, Arthrobacter sp. D2 could completely remove $100 \mathrm{mg} / \mathrm{L} \mathrm{SDZ}$ within $27 \mathrm{~h}$ (Deng et al., 2016). The maximal removal rate of $100 \mathrm{mg} / \mathrm{L}$ SMX by Pseudomonas psychrophila strain HA-4 was $34.30 \%$ after 192 h (Jiang et al., 2014), while Aeromonas sp., Kluyvera sp., and Raoultella sp. could transform $11 \%-73 \%$ of the initial $200 \mu$ M SMX after 15 days (Reis et al., 2018a), and bacteria co-metabolism could transform $98 \%$ of the initial $0.4 \mu$ M SMX in 1 day (Kassotaki et al., 2016). 


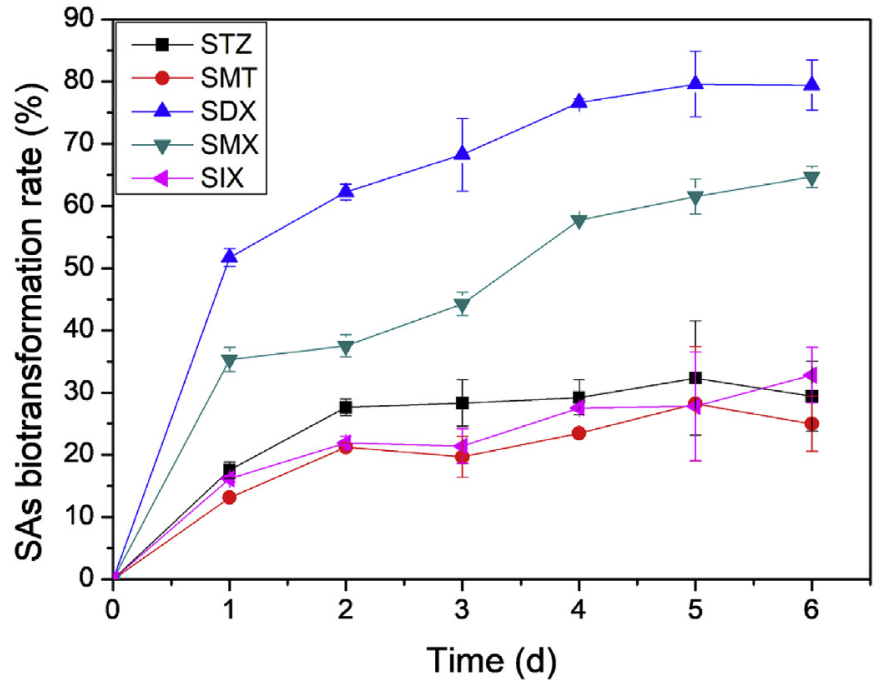

Fig. 3. The time course of SAs biotransformation rates by strain L2-2. SAs consisted of STZ, SMT, SDX, SMX and SIX with an initial concentration of $4 \mathrm{mg}$ / $\mathrm{L}$ respectively. The data were expressed as the means \pm SD from three replicates.

\subsection{Effects of influential factors on SAs biotransformation}

As shown in Fig. 4, when the initial concentration was less than $5 \mathrm{mg} / \mathrm{L}$, the biotransformation rates seemed almost stable; while a sharp decrease was observed when it was more than $5 \mathrm{mg} / \mathrm{L}$, with the biotransformation rates decreased from $91.68 \%$ to $26.17 \%$ for SDX and decreased by about $80 \%$ for other SAs when SAs concentration increased from $5 \mathrm{mg} / \mathrm{L}$ to $50 \mathrm{mg} / \mathrm{L}$. The result of this study suggested that the SAs initial concentrations could greatly affect SAs biotransformation efficiencies by strain L2-2. It also should be noted that the experiment was conducted with a mixture of 5 SAs (STZ, SMT, SDX, SMX and SIX), and the total SAs were 5 times the SAs initial concentration, indicating that strain L2-2 could resist and transform SAs at concentrations as high as $250 \mathrm{mg} / \mathrm{L}$, which was higher than Shewanella oneidensis (60 mg/L) (Mao et al., 2018) and Pseudomonas psychrophila (200 mg/L) (Jiang et al., 2014).

Significant variations in biotransformation rates of STZ, SMT, SDX, SMX and SIX by strain L2-2 were observed for different $\mathrm{pH}$ values $(\mathrm{P}<0.05)$ (Fig. 4). Neutral or weak alkaline conditions facilitated the SAs biotransformation by strain L2-2, with $\mathrm{pH}$ 7-8 being the optimal condition for most SAs. Higher bio-removal efficiencies of SMX at $\mathrm{pH}$ 7.0 or 8.0 were also observed for Shewanella oneidensis (Mao et al., 2018). In water samples from highly polluted rivers, the aerobic bioremoval efficiency of SAs was also reported to be positively correlated with pH (Adamek et al., 2016). However, opposite results have been reported for photodegradation, the degradation of SAs was significantly enhanced in acidic pH conditions (Avisar et al., 2010; Lester et al., 2012). The varied effects of $\mathrm{pH}$ on bio-removal and photodegradation were probably that, $\mathrm{pH}$ values could influence the reproduction and numbers of bacterial strains, as well as bacteria enzyme activity in vitro and vivo, and Acinetobacter sp. showed better performance in SMX degradation under neutral condition than acidic condition, which was closely linked to strain growth (Wang and Wang, 2018a, 2018b). Some studies also suggested that $\mathrm{pH}$ could sensitively affect the accumulation of SAs in bacterial cells by affecting the concentration of the effective anionic species (Zarfl et al., 2008).

The biotransformation rates of SAs could also be significantly affected by salinities $(\mathrm{P}<0.01)$, with higher biotransformation
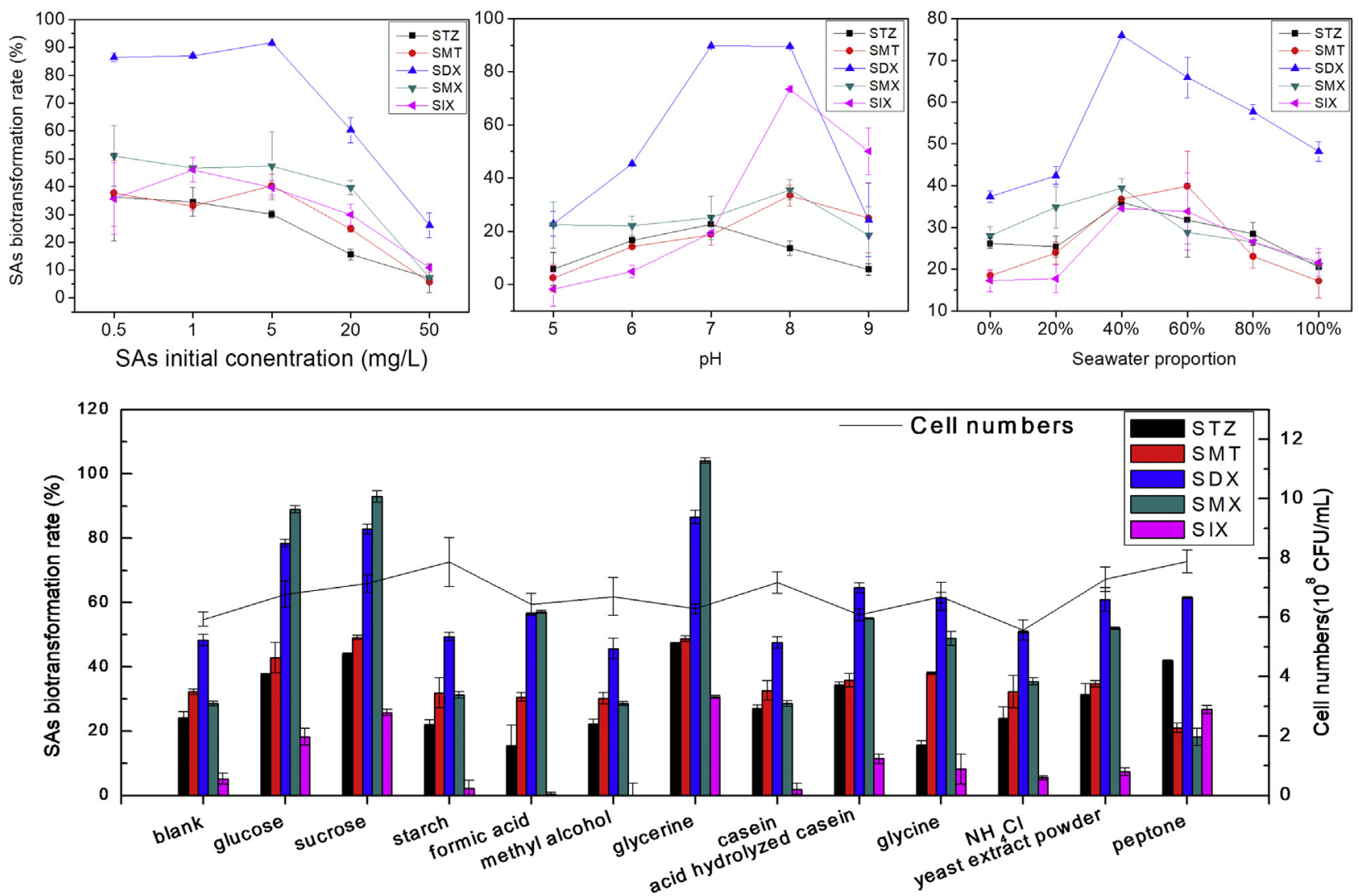

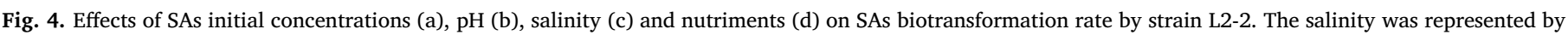

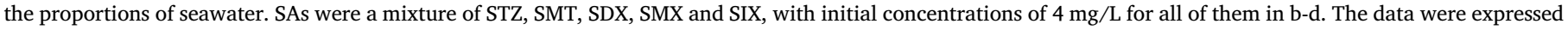
as the means \pm SD from three replicates. 
efficiencies found in salinity from $13.93 \%$ to $20.89 \%$ while low efficiencies found in either freshwater (salinity $0 \% 0$ ) or seawater (salinity $34.82 \%$ ) (Fig. 4). Most previous studies indicated that salinity was negative to sulfonamide bio-removal in river water (Adamek et al., 2016) and activated sludge (Li and Zhang, 2010). In this study, stain L22 , screened from estuary water, could endure a high range of salinities after long-term evolution and accommodation. The best performance of strain L2-2 was observed in salinity between seawater and fresh water, implying the uniqueness of stain L2-2.

Since the biotransformation mechanism of SAs by strain L2-2 was acetylation with the introduction of an acetyl group into the nitrogen atoms of molecules, additional carbon resources could theoretically facilitate SAs biotransformation. Besides, additional carbon and nitrogen sources could increase the cell numbers of strain L2-2, thus enhancing biotransformation. Therefore, the effects of additional carbon and nitrogen sources on SAs biotransformation were investigated. As shown in Fig. 4, SMX was the most influenced antibiotic by additional nutriments. For blank, the biotransformation rate of SMX was lower than SDX, but when the medium was added with $1 \mathrm{~g} / \mathrm{L}$ glucose, sucrose or glycerine, the SMX biotransformation efficiency became higher than SDX. Notably, additional glycerine would increase the SMX biotransformation efficiency from $28.54 \%$ to $100 \%$. Monosaccharide, disaccharide, formic acid, acid hydrolyzed casein, glycine, and yeast extract powder could also increase SMX biotransformation obviously. Similarly, glucose, sucrose, and glycerine could enhance SDX biotransformation. Compared with SMX and SDX, the influence of nutriments on SIX was slightly different, higher SIX biotransformation observed for glucose, sucrose, glycerine, and peptone, while formic acid, methyl alcohol, and casein showed obvious negative effect. The effects of nutriments on STZ and SMT were not obvious, and their optimal nutriments were glycerine and sucrose, respectively. Generally, compared with SAs as the sole carbon source, additional nutriments except $\mathrm{NH}_{4} \mathrm{Cl}$ could enhance the biotransformation of SAs by increasing the cell numbers (Fig. 4). Exceptions were found for formic acid, methyl alcohol, and casein. Although they could facilitate the growth of strain L2-2, they all showed inhibitions to SIX biotransformations. Conversely, while the growth promotion of glycerine was not significant, it showed greater acceleration to SAs biotransformation than other nutriments. Some previous studies showed that additional carbon could enhance SAs biodegradation (Müller et al., 2013; Nguyen et al., 2017), but the mechanisms of the effects of different carbon sources on SAs biodegradation were mostly unknown. Studies showed that acetyl-coenzyme A occupied a critical position in protein acetylation (Pietrocola et al., 2015; Mews et al., 2017), while glucose and glycerine could cause acetyl-coenzyme A to increase quickly in vivo (Chohnan et al., 1998), which might further increase SAs biotransformation efficiencies. Notably, the results in this study showed that the effects were nutrient specific and SAs specific, which could not be fully explained by the known mechanisms and further explorations are needed.

From the above, SAs initial concentrations, $\mathrm{pH}$ and nutrients could all significantly affect SAs biotransformation efficiencies by strain L2-2. The overall optimal conditions for SAs biotransformation were determined to be less than $20 \mathrm{mg} / \mathrm{L}$ for single sulfonamide or less than $100 \mathrm{mg} / \mathrm{L}$ for total SAs in the neutral or weakly alkaline medium. The optimal salinity was $10-20 \%$, and additional nutrients like glucose, sucrose or glycerine could enhance bio-removal.

\subsection{Toxicity analysis of SAs and their metabolites}

After 10 days of metabolization by strain L2-2, biotransformation rates of single STZ, SMT, SDX, SMX, SIX and their mixture (SAs-MIX) were $41.64 \pm 2.27,25.95 \pm 4.29,65.46 \pm 4.58,25.61 \pm 0.09$, $35.16 \pm 1.36$ and $34.07 \pm 2.68 \%$, respectively (Fig. 5). Correspondingly, except for SMT, E. coli growth inhibitory rate of the SAs and SAs-MIX decreased significantly after microbial metabolism, especially for STZ, whose inhibition towards E. coli disappeared basically, indicating that the toxicity of STZ could be eliminated by strain L2-2. The reduction of the toxicity by metabolization implied that the acetylated metabolites of most SAs seemed less toxic, which could be partially demonstrated by the findings that $N^{4}$-AcSMX, the metabolite of SMX, barely showed an inhibitory effect on E. coli growth (Fig. 5). The results were consistent with previous reports that while for some SAs such as SPD, their acetylated metabolites were still toxic (GarcíaGalán et al., 2012), but the acetylated metabolites of SDM, SMX, and SDZ had much weaker growth inhibitory effects on green algae (Eguchi et al., 2004) and $N^{4}$-acetyl-derivatives of SMX retained less than $10 \%$ of the effect of SMX on bacteria growth (Majewsky et al., 2014).

\subsection{Genes related to sulfonamide biotransformation}

According to the genome annotations, among the total 5603 genes 4837 were coding genes, and compared to the reported partial Vibrio sp. genome, strain L2-2 had more total genes and coding genes (Table S1). According to statistics, a total of 4264 eggNOG, 2604 KO, and 3494 GO were annotated in strain L2-2 genome (Table S2). Study had shown that Arylamine $N$-acetyltransferase (ANT) gene banat $C$ from Bacillus anthracis had strong NAT activity toward SMX and expression of banatC in Escherichia coli afforded higher-than-normal resistance to SMX (Pluvinage et al., 2007). So genes noted with $N$-acetyltransferase were selected, and among them, genes which E-value was less 0.0001 compared with CARD were finally determined to the hypothetic genes termed $v$ dnatA-G (Table S3). It should be pointed out that gene $v$ dnat $G$ was not matched with genes in CARD, but its coding protein with 268 amino acids was similar to NAT enzymes (270-290 amino acids) (Pluvinage et al., 2007).

The expression of gene $v d n a t B, v d n a t C$, $v d n a t E$, and $v d n a t F$ in groups with and without SMX treatment did not show a significant difference $(\mathrm{P}>0.05)$, while the expression of gene $v$ dnatA, $v$ dnatD, and $v d n a t G$ were significantly higher in SMX biotransformation process than the control groups (Fig. 6), and the gene sequence could be found in strain L2-2 genome sequence with NCBI accession number JAANXJ000000000.

By comparing with CARD, vdnatA was identified as AAC(3) which was defined as acetylation of the aminoglycoside antibiotic on the amino group at position 3 (Allmansberger et al., 1985), and $v$ dnatD was identified to Mycobacterium tuberculosis gyrA conferring resistance to fluoroquinolones. $v d n a t G$ encoding protein shared $95.1 \%$ sequence identity to putative N-hydroxyarylamine O-acetyltransferase of $V$. parahaemolyticus (UniProtKB-Q87K26) and $48.9 \%$ sequence identity to Arylamine $N$-acetyltransferase of $V$. quintilis (UniProtKBA0A1M7YQX1). Among the three genes, the expression level of gene $v$ dnat $A$ and $v$ dnat $G$ obviously decreased with time after $24 \mathrm{~h}$, and this change was conformed to the SMX biotransformation rate in Fig. 3, which obviously decreased after $24 \mathrm{~h}$. However, changes in gene $v$ dnat $D$ expression level were not obvious between $24 \mathrm{~h}$ and $48 \mathrm{~h}$. So vdnatA and $v$ dnat $G$ were more likely to be the key genes involved in SMX biotransformation. Some previous studies have proposed that NAT-coding genes would play a vital role in SMX transformation. Reis et al. found nat gene in strain Proteobacteria mandelii McBPA4 and McBRA2 could transform SMX to Ac-SMX (Reis et al., 2018a). Larcher et al. also hypothesized that Rhodococcus equi producing NAT resulted in SMX removal (Larcher and Yargeau, 2011).

Acetylation is an important metabolic pathway for resistance, detoxification, and inactivation for drugs such as aminoglycosides (Soleimani et al., 2018), fluoroquinolone (Kim et al., 2013), streptothricin (Burckhardt and Escalante-Semerena, 2017), and others. NAT has been confirmed to catalyze the acetyl-CoA-dependent $\mathrm{N}$-acetylation of various arylamines and their N-hydroxylated metabolites (WEBER, 1985). According to previous researches, NAT has already been linked to sulfonamide metabolism and detoxification in humans, however, it has not been confirmed if it is directly related to sulfonamide acetylation in bacterium (Cribb et al., 1993; Kagaya et al., 2012). The gene 


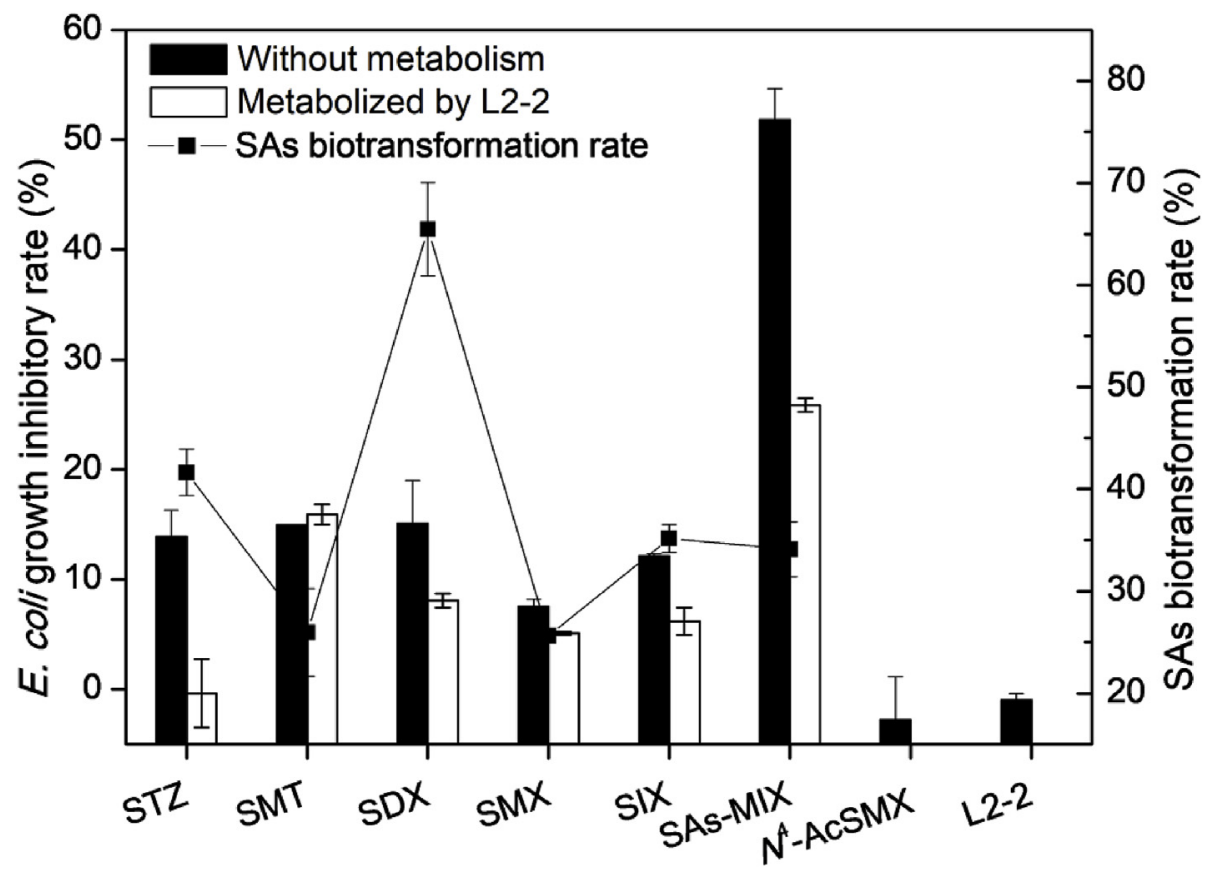

Fig. 5. Escherichia coli growth-inhibitory of SAs with and without metabolizing by strain L2-2. The concentrations of STZ, SMT, SDX, SMX, SIX and $N^{4}$-AcSMX were all $20 \mathrm{mg} / \mathrm{L}$, and SAs-MIX represented a mixture of STZ, SMT, SDX, SMX and SIX. The data were expressed as the means \pm SD from three replicates.

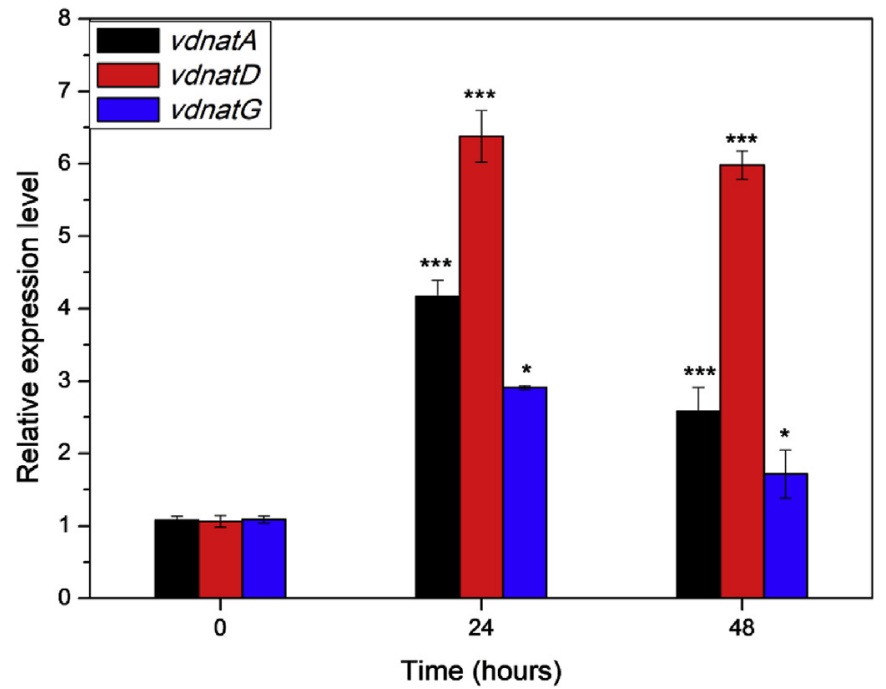

Fig. 6. Relative expression of gene $v d n a t A, v d n a t D$, and $v d n a t G$ of strain L2-2 with SMX stress by RT-PCR. The data were expressed as the means \pm SD from three replicates. Significant difference compared with the control group at the same time was marked with *p $<0.05,{ }^{* *} \mathrm{p}<0.01$, ***p $<0.001$.

panat for NAT from Pseudomonas aeruginosa could express as an Nterminal histidine-tagged protein in $E$. coli, and the purified enzyme could acetylize arylamine (Westwood et al., 2005), and sulfonamides have an arylamine structure. Mulyono et al. found that Bacillus cereus strain 10-L-2 could produce NAT which could transform 4-phenylenediamine into 4-aminoacetanilide (Mulyono et al., 2007). However, the NAT expressed by $v$ dnatA and $v$ dnat $G$ shared only low sequence identity at the amino acid level (8.2\% and $29.8 \%$ with NAT from Pseudomonas aeruginosa UniProtKB-Q9HUY3, $7.5 \%$ and $24.9 \%$ with NAT from $\mathrm{Ba}$ cillus cereus UniProtKB- B7X9H5). Based on these results, $v$ dnat $G$ was more likely to be the key gene of strain L2-2 to transform SAs. The role of gene $v$ dnatA deserved further studies.

In addition, by comparison with sequences in the GenBank database, vdnat $G$ was found in some other Vibrio sp. mainly including $V$. diabolicus, V. antiquarius and V. parahaemolyticus, some strains' NCBI sequence ID was listed - CP014095.1, CP014133.1, AP022866.1, AP022860.1, CP028482.1. But except V. diabolicus strain FDAARGOS_96, the percent identity of other strains not totally matched with strain L2-2. Therefore, SAs acetylation capacity might appear on several Vibrio sp. strains. But, Xu et al. found that only less than $1 \%$ of the SMX was transformed into $N^{4}$-acetyl-sulfamethoxazole based on water-sediment batch experiments using bacterial community (Xu et al., 2011), and this suggested that SAs acetylation was not a common phenomenon in bacterium. The expression of gene $v$ dnatA and $v$ dnat $G$ in the SMX treatment group increased significantly, and their rising trend basically matched to SMX biotransformation process, especially $v$ dnat $G$ whose gene length was basically consistent with the known NAT (Yamamura et al., 2000). Some research had explored genes relevant with SMX acetylation, but so far as we know, there was no definite validation of SMX acetylation gene by cloning and expression.

\section{Conclusion}

V. diabolicus strain L2-2, capable of transforming many SAs to their $N^{4}$-acetylated metabolites, was isolated and identified. Through comparison to many kinds of compounds containing phenylamino group or $p$-ABS and its analogs, SAs with N-oxides of heterocyclic structure were easier to be acetylated. Gene $v d n a t A$ and $v d n a t G$ might be the key gene in SAs acetylation process, which might code Arylamine $\mathrm{N}$-acetyltransferase. After acetylization by strain L2-2, the toxicities of SAs towards $E$. coli were significantly decreased. Optimum metabolic conditions of strain L2-2 towards SAs turned out to be neutral or weakly alkaline, with less than $100 \mathrm{mg} / \mathrm{L}$ of total SAs concentrations in salinity of $10-20 \%$, and additional nutriments of $1 \mathrm{~g} / \mathrm{L}$ glucose, sucrose or glycerine. The known microorganisms capable of metabolizing SAs were mostly isolated from freshwater environment, this study first reported a strain of $V$. diabolicus that could biodegrade a broad class of SAs in seawater. And the results in this study provided a strategy for simultaneous biotransformation and detoxification of SAs contamination in the estuary environment. 


\section{CRediT authorship contribution statement}

Qiaoning Wang: Conceptualization, Methodology, Investigation, Writing - original draft, Investigation. Yaru Jiang: Methodology, Data curation, Validation. Hongdan Wang: Methodology, Writing - review \& editing. Xianbo Chang: Methodology, Investigation. Min Lv: Validation, Writing - review \& editing. Lingxin Chen: Funding acquisition, Project administration, Supervision, Writing - review \& editing.

\section{Declaration of competing interest}

The authors declare no competing financial interest.

\section{Acknowledgments}

This work was financially supported by the National Natural Science Foundation of China (41601525), the Key Research and Development Project of Shandong Province of China (2018GSF116011), the Key Research and Development Project of Yantai City (2017ZH093), the Project of Science and Technology Development of Shandong Province of China (2013YD21010), Science and Technology Development Plan of Yantai (2017ZH089) and the Taishan Scholar Project Special Funding (ts20190962).

\section{Appendix A. Supplementary data}

Supplementary data to this article can be found online at https:// doi.org/10.1016/j.envres.2020.109718.

\section{References}

Adamek, E., Baran, W., Sobczak, A., 2016. Assessment of the biodegradability of selected sulfa drugs in two polluted rivers in Poland: effects of seasonal variations, accidental contamination, turbidity and salinity. J. Hazard. Mater. 313, 147-158.

Allmansberger, R., Brau, B., Piepersberg, W., 1985. Genes for gentamicin-(3)-N-acetyltransferases III and IV. II. Nucleotide sequences of three AAC(3)-III genes and evolutionary aspects. Mol Gen Genet 198, 514-520.

Avisar, D., Lester, Y., Mamane, H., 2010. pH induced polychromatic UV treatment for the removal of a mixture of SMIX, OTC and CIP from water. J. Hazard. Mater. 175, 1068-1074.

Bankevich, A., Nurk, S., Antipov, D., Gurevich, A.A., Dvorkin, M., Kulikov, A.S., Lesin, V.M., Nikolenko, S.I., Pham, S., Prjibelski, A.D., 2012. SPAdes: a new genome assembly algorithm and its applications to single-cell sequencing. J Comput Biol 19, 455-477.

Batt, A.L., Snow, D.D., Aga, D.S., 2006. Occurrence of sulfonamide antimicrobials in private water wells in Washington County, Idaho, USA. Chemosphere 64, 1963-1971.

Besemer, J., Lomsadze, A., Borodovsky, M., 2001. GeneMarkS: a self-training method for prediction of gene starts in microbial genomes. Implications for finding sequence motifs in regulatory regions. Nucleic Acids Res 29, 2607-2618.

Boreen, A.L., Arnold, W.A., McNeill, K., 2004. Photochemical fate of sulfa drugs in the aquatic environment: sulfa drugs containing five-membered heterocyclic groups. Environ. Sci. Technol. 38, 3933-3940.

Buchfink, B., Xie, C., Huson, D.H., 2015. Fast and sensitive protein alignment using DIAMOND. Nat Methods 12, 59.

Burckhardt, R.M., Escalante-Semerena, J.C., 2017. In Bacillus subtilis, the SatA (formerly YyaR) acetyltransferase detoxifies streptothricin via lysine acetylation. Appl. Environ. Microbiol. 83 e01590-01517.

Cabello, F.C., Godfrey, H.P., Tomova, A., Ivanova, L., Dölz, H., Millanao, A., Buschmann, A.H., 2013. Antimicrobial use in aquaculture re-examined: its relevance to antimicrobial resistance and to animal and human health. Environ. Microbiol. 15, 1917-1942.

Chen, J., Xie, S., 2018. Overview of sulfonamide biodegradation and the relevant pathways and microorganisms. Sci. Total Environ. 640-641, 1465-1477.

Chohnan, S., Izawa, H., Nishihara, H., Takamura, Y., 1998. Changes in size of intracellular pools of coenzyme A and its thioesters in Escherichia coli K-12 cells to various carbon sources and stresses. Biosci., Biotechnol., Biochem. 62, 1122-1128.

Ciufo, S., Kannan, S., Sharma, S., Badretdin, A., Clark, K., Turner, S., Brover, S., Schoch, C.L., Kimchi, A., DiCuccio, M., 2018. Using average nucleotide identity to improve, taxonomic assignments in prokaryotic genomes at the NCBI. Int. J. Syst. Evol. Microbiol. 68, 2386-2392.

Coil, D., Jospin, G., Darling, A.E., 2015. A5-miseq: an updated pipeline to assemble microbial genomes from Illumina MiSeq data. Bioinformatics 31, 587-589.

Cribb, A.E., Nakamura, H., Grant, D.M., Miller, M.A., Spielberg, S.P., 1993. Role of polymorphic and monomorphic human arylamine N-acetyltransferases in determining sulfamethoxazole metabolism. Biochem. Pharmacol. 45, 1277-1282.

Deng, Y., Mao, Y., Li, B., Yang, C., Zhang, T., 2016. Aerobic degradation of sulfadiazine by
Arthrobacter spp.: kinetics, pathways, and genomic characterization. Environ. Sci. Technol. 50, 9566-9575.

Eguchi, K., Nagase, H., Ozawa, M., Endoh, Y.S., Goto, K., Hirata, K., Miyamoto, K., Yoshimura, H., 2004. Evaluation of antimicrobial agents for veterinary use in the ecotoxicity test using microalgae. Chemosphere $57,1733-1738$.

Federhen, S., Rossello-Mora, R., Klenk, H.-P., Tindall, B.J., Konstantinidis, K.T., Whitman, W.B., Brown, D., Labeda, D., Ussery, D., Garrity, G.M., Colwell, R.R., Hasan, N., Graf, J., Parte, A., Yarza, P., Goldberg, B., Sichtig, H., Karsch-Mizrachi, I., Clark, K., McVeigh, R., Pruitt, K.D., Tatusova, T., Falk, R., Turner, S., Madden, T., Kitts, P., Kimchi, A., Klimke, W., Agarwala, R., DiCuccio, M., Ostell, J., 2016. Meeting report: GenBank microbial genomic taxonomy workshop (12-13 May, 2015). Stand Genomic Sci $11,15$.

García-Galán, M.J., Silvia Díaz-Cruz, M., Barceló, D., 2008. Identification and determination of metabolites and degradation products of sulfonamide antibiotics. TrACTrends Anal. Chem. 27, 1008-1022.

García-Galán, M.J., González Blanco, S., López Roldán, R., Díaz-Cruz, S., Barceló, D., 2012. Ecotoxicity evaluation and removal of sulfonamides and their acetylated metabolites during conventional wastewater treatment. Sci. Total Environ. 437, 403-412.

Gauthier, H., Yargeau, V., Cooper, D.G., 2010. Biodegradation of pharmaceuticals by Rhodococcus rhodochrous and Aspergillus niger by co-metabolism. Sci. Total Environ. 408, 1701-1706.

Gaze, W., Depledge, M., 2017. Antimicrobial resistance: investigating the environmental dimension-Frontiers 2017: emerging issues of environmental concern. In: Programme, U.N.E. (Ed.), pp. 12-22.

Geng, C.N., Bergheaud, V., Gamier, P., Zhu, Y.G., Haudin, C.S., 2018. Impact of sludge treatments on the extractability and fate of acetyl sulfamethoxazole residues in amended soils. Chemosphere 194, 828-836.

Gómez-Ramos, M.d.M., Mezcua, M., Agüera, A., Fernández-Alba, A.R., Gonzalo, S., Rodríguez, A., Rosal, R., 2011. Chemical and toxicological evolution of the antibiotic sulfamethoxazole under ozone treatment in water solution. J. Hazard. Mater. 192, 18-25.

Gothwal, R., Shashidhar, T., 2015. Antibiotic pollution in the environment: a Review, CLEAN-Soil. Air, Water 43, 479-489.

Guo, X., Zhu, Z., Li, H., 2014. Biodegradation of sulfamethoxazole by Phanerochaete chrysosporium. J. Mol. Liq. 198, 169-172.

Harnisch, F., Gimkiewicz, C., Bogunovic, B., Kreuzig, R., Schröder, U., 2013. On the removal of sulfonamides using microbial bioelectrochemical systems. Electrochem. Commun. 26, 77-80.

Homem, V., Santos, L., 2011. Degradation and removal methods of antibiotics from aqueous matrices - a review. J. Environ. Manage. 92, 2304-2347.

Ingerslev, F., Halling-Sørensen, B., 2000. Biodegradability properties of sulfonamides in activated sludge. Environ. Toxicol. Chem. 19, 2467-2473.

Jiang, B., Li, A., Cui, D., Cai, R., Ma, F., Wang, Y., 2014. Biodegradation and metabolic pathway of sulfamethoxazole by Pseudomonas psychrophila HA-4, a newly isolated cold-adapted sulfamethoxazole-degrading bacterium. Appl. Microbiol. Biotechnol. 98, 4671-4681.

Kagaya, H., Miura, M., Niioka, T., Saito, M., Numakura, K., Habuchi, T., Satoh, S, 2012 Influence of NAT2 polymorphisms on sulfamethoxazole pharmacokinetics in renal transplant recipients. Antimicrob. Agents Chemother. 56, 825-829.

Kassotaki, E., Buttiglieri, G., Ferrando-Climent, L., Rodriguez-Roda, I., Pijuan, M., 2016 Enhanced sulfamethoxazole degradation through ammonia oxidizing bacteria cometabolism and fate of transformation products. Water Res 94, 111-119.

Kim, D.-W., Feng, J., Chen, H., Kweon, O., Gao, Y., Yu, L.-R., Burrowes, V.J., Sutherland, J.B., 2013. Identification of the enzyme responsible for $N$-acetylation of norfloxacin by Microbacterium sp. strain 4N2-2. Appl. Environ. Microbiol 79, 314-321.

Kolpin, D.W., Furlong, E.T., Meyer, M.T., Thurman, E.M., Zaugg, S.D., Barber, L.B., Buxton, H.T., 2002. Pharmaceuticals, hormones, and other organic wastewater contaminants in U.S. Streams, 1999-2000: A national reconnaissance. Environ. Sci. Technol. 36, 1202-1211.

Larcher, S., Yargeau, V., 2011. Biodegradation of sulfamethoxazole by individual and mixed bacteria. Appl. Microbiol. Biotechnol. 91, 211-218.

Lester, Y., Mamane, H., Avisar, D., 2012. Enhanced removal of micropollutants from groundwater, using $\mathrm{pH}$ modification coupled with photolysis, Water, Air. Soil Pollut $223,1639-1647$.

Li, B., Zhang, T., 2010. Biodegradation and adsorption of antibiotics in the activated sludge process. Environ. Sci. Technol. 44, 3468-3473.

Lian, J., Qiang, Z., Li, M., Bolton, J.R., Qu, J., 2015. UV photolysis kinetics of sulfonamides in aqueous solution based on optimized fluence quantification. Water Res 75 , 43-50.

Majewsky, M., Wagner, D., Delay, M., Bräse, S., Yargeau, V., Horn, H., 2014. Antibacterial activity of sulfamethoxazole transformation products (TPs): general relevance for sulfonamide TPs modified at the para position. Chem. Res. Toxicol. 27, 1821-1828.

Mao, F., Liu, X., Wu, K., Zhou, C., Si, Y., 2018. Biodegradation of sulfonamides by Shewanella oneidensis MR-1 and Shewanella sp. strain MR-4. Biodegradation 29 , 129-140.

Men, Y., Achermann, S., Helbling, D.E., Johnson, D.R., Fenner, K., 2017. Relative contribution of ammonia oxidizing bacteria and other members of nitrifying activated sludge communities to micropollutant biotransformation. Water Res 109, 217-226.

Mews, P., Donahue, G., Drake, A.M., Luczak, V., Abel, T., Berger, S.L., 2017. Acetyl-CoA synthetase regulates histone acetylation and hippocampal memory. Nature 546, 381.

Mo, W.Y., Chen, Z., Leung, H.M., Leung, A.O.W., 2017. Application of veterinary antibiotics in China's aquaculture industry and their potential human health risks. Environ. Sci. Pollut. Res. 24, 8978-8989.

Müller, E., Schüssler, W., Horn, H., Lemmer, H., 2013. Aerobic biodegradation of the sulfonamide antibiotic sulfamethoxazole by activated sludge applied as co-substrate 
and sole carbon and nitrogen source. Chemosphere 92, 969-978.

Mulyono, S. Takenaka, Sasano, Y., Murakami, S., Aoki, K., 2007. Bacillus cereus strain 10$\mathrm{L}-2$ produces two arylamine $\mathrm{N}$-acetyltransferases that transform 4-phenylenediamine into 4-aminoacetanilide. J. Biosci. Bioeng. 103, 147-154.

Nguyen, P.Y., Carvalho, G., Reis, A.C., Nunes, O.C., Reis, M.A.M., Oehmen, A., 2017 Impact of biogenic substrates on sulfamethoxazole biodegradation kinetics by Achromobacter denitrificans strain PR1. Biodegradation 28, 205-217.

Novo, A., André, S., Viana, P., Nunes, O.C., Manaia, C.M., 2013. Antibiotic resistance, antimicrobial residues and bacterial community composition in urban wastewater. Water Res 47, 1875-1887.

Pietrocola, F., Galluzzi, L., Bravo-San Pedro, José M., Madeo, F., Kroemer, G., 2015. Acetyl coenzyme A: a central metabolite and second messenger. Cell Metab 21, 805-821.

Pluvinage, B., Dairou, J., Possot, O.M., Martins, M., Fouet, A., Dupret, J.-M., RodriguesLima, F., 2007. Cloning and molecular characterization of three arylamine N-acetyltransferase genes from Bacillus anthracis: identification of unusual enzymatic properties and their contribution to sulfamethoxazole resistance. Biochemistry 46, 7069-7078.

Radke, M., Lauwigi, C., Heinkele, G., Mürdter, T.E., Letzel, M., 2009. Fate of the antibiotic sulfamethoxazole and its two major human metabolites in a water sediment test. Environ. Sci. Technol. 43, 3135-3141.

Reis, P.J.M., Homem, V., Alves, A., Vilar, V.J.P., Manaia, C.M., Nunes, O.C., 2018a. Insights on sulfamethoxazole bio-transformation by environmental Proteobacteria isolates. J. Hazard. Mater. 358, 310-318.

Reis, A.C., Čvančarová, M., Liu, Y., Lenz, M., Hettich, T., Kolvenbach, B.A., Corvini, P.F.X., Nunes, O.C., 2018b. Biodegradation of sulfamethoxazole by a bacterial consortium of Achromobacter denitrificans PR1 and Leucobacter sp. GP. Appl. Microbiol. Biotechnol. 102, 10299-10314.

Ricken, B., Fellmann, O., Kohler, H.P.E., Schäffer, A., Corvini, P.F.X., Kolvenbach, B.A., 2015. Degradation of sulfonamide antibiotics by Microbacterium sp. strain BR1 elucidating the downstream pathway. New Biotechnol 32, 710-715.

Rodríguez-Rodríguez, C.E., Jesús García Galán, M., Blánquez, P., Díaz-Cruz, M.S., Barceló, D., Caminal, G., Vicent, T., 2012. Continuous degradation of a mixture of sulfonamides by Trametes versicolor and identification of metabolites from sulfapyridine and sulfathiazole. J. Hazard. Mater. 213-214, 347-354.

Sarmah, A.K., Meyer, M.T., Boxall, A.B.A., 2006. A global perspective on the use, sales, exposure pathways, occurrence, fate and effects of veterinary antibiotics (VAs) in the environment. Chemosphere 65, 725-759.

Schmittgen, T.D., Livak, K.J., 2008. Analyzing real-time PCR data by the comparative CT method. Nat Protoc 3, 1101-1108.

Segura, P.A., François, M., Gagnon, C., Sauvé, S., 2009. Review of the occurrence of antiinfectives in contaminated wastewaters and natural and drinking waters. Environ. Health Perspect. 117, 675-684.

Shi, H., Yang, Y., Liu, M., Yan, C., Yue, H., Zhou, J., 2014. Occurrence and distribution of antibiotics in the surface sediments of the Yangtze Estuary and nearby coastal areas. Mar. Pollut. Bull. 83, 317-323.

Soleimani, S., Vaziri, S., Afrasiyabi, M., Nazem, H., Fazilati, M., 2018. Survey of aminoglycoside acetyl transferase genes in multi-drug resistance acinetobacter. MOJ Toxicol 4, 00082.

Su, T., Deng, H., Benskin, J.P., Radke, M., 2016. Biodegradation of sulfamethoxazole photo-transformation products in a water/sediment test. Chemosphere 148 , 518-525.

Sukul, P., Spiteller, M., 2006. Sulfonamides in the environment as veterinary drugs. In: Rev. Environ. Contam. T. Springer, pp. 67-101.
Walker, B.J., Abeel, T., Shea, T., Priest, M., Abouelliel, A., Sakthikumar, S., Cuomo, C.A., Zeng, Q., Wortman, J., Young, S.K., 2014. Pilon: an integrated tool for comprehensive microbial variant detection and genome assembly improvement. PloS one 9.

Wang, J., Wang, S., 2018a. Microbial degradation of sulfamethoxazole in the environment. Appl. Microbiol. Biotechnol. 102, 3573-3582.

Wang, S., Wang, J., 2018b. Biodegradation and metabolic pathway of sulfamethoxazole by a novel strain Acinetobacter sp. Appl. Microbiol. Biotechnol. 102, 425-432.

Weber, W.W., 1985. N-acetylation pharmacogenetics. Pharmacol Rev 37, 25-79.

Westwood, I.M., Holton, S.J., Rodrigues-Lima, F., Dupret, J.-M., Bhakta, S., Noble, M.E., Sim, E., 2005. Expression, purification, characterization and structure of Pseudomonas aeruginosa arylamine N-acetyltransferase. Biochem. J. 385, 605-612.

Xiong, W., Sun, Y., Zhang, T., Ding, X., Li, Y., Wang, M., Zeng, Z., 2015. Antibiotics, antibiotic resistance genes, and bacterial community composition in fresh water aquaculture environment in China. Microb. Ecol. 70, 425-432.

Xu, B., Mao, D., Luo, Y., Xu, L., 2011. Sulfamethoxazole biodegradation and biotransformation in the water-sediment system of a natural river. Bioresour. Technol. 102, 7069-7076.

Yamamura, E.T., Sayama, M., Kakikawa, M., Mori, M.-a., Taketo, A., Kodaira, K.-I., 2000. Purification and biochemical properties of an N-hydroxyarylamine O-acetyltransferase from Escherichia coli. Biochimica et Biophysica Acta-General Subjects 1475, 10-16.

Yan, M., Xu, C., Huang, Y., Nie, H., Wang, J., 2018. Tetracyclines, sulfonamides and quinolones and their corresponding resistance genes in the Three Gorges Reservoir, China,. Sci. Total Environ. 631-632, 840-848.

Yang, S., Lin, C., Wu, C., Ng, K., Yu Chen Lin, A., Andy Hong, P.-K., 2012. Fate of sulfonamide antibiotics in contact with activated sludge - sorption and biodegradation. Water Res 46, 1301-1308.

Yang, C.W., Hsiao, W.C., Chang, B.V., 2016. Biodegradation of sulfonamide antibiotics in sludge. Chemosphere 150, 559-565.

Ye, Z., Weinberg, H.S., Meyer, M.T., 2007. Trace analysis of trimethoprim and sulfonamide, macrolide, quinolone, and tetracycline antibiotics in chlorinated drinking water using liquid chromatography electrospray tandem mass spectrometry. Anal. Chem. 79, 1135-1144.

Zarfl, C., Matthies, M., Klasmeier, J., 2008. A mechanistical model for the uptake of sulfonamides by bacteria. Chemosphere 70, 753-760.

Zhang, W., Wen, Y., Niu, Z., Yin, K., Xu, D., Chen, L., 2012a. Isolation and characterization of sulfonamide-degrading bacteria Escherichia sp. HS21 and Acinetobacter sp. HS51. World J. Microbiol. Biotechnol. 28, 447-452.

Zhang, W., Xu, D., Niu, Z., Yin, K., Liu, P., Chen, L., 2012b. Isolation and characterization of Pseudomonas sp. DX7 capable of degrading sulfadoxine. Biodegradation 23, 431-439.

Zhang, W., Niu, Z., Liao, C., Chen, L., 2013. Isolation and characterization of Pseudomonas sp. strain capable of degrading diethylstilbestrol. Appl. Microbiol. Biotechnol. 97, 4095-4104.

Zhang, Q., Ying, G., Pan, C., Liu, Y., Zhao, J., 2015. Comprehensive evaluation of antibiotics emission and fate in the river basins of China: source analysis, multimedia modeling, and linkage to bacterial resistance. Environ. Sci. Technol. 49, 6772-6782.

Zhang, Y., Zhou, J., Xu, Q., Cheng, J., Luo, Y., Yuan, Y., 2016. Exogenous cofactors for the improvement of bioremoval and biotransformation of sulfamethoxazole by Alcaligenes faecalis. Sci. Total Environ. 565, 547-556.

Zheng, S., Qiu, X., Chen, B., Yu, X., Liu, Z., Zhong, G., Li, H., Chen, M., Sun, G., Huang, H., Yu, W., Freestone, D., 2011. Antibiotics pollution in Jiulong River estuary: source, distribution and bacterial resistance. Chemosphere 84, 1677-1685. 